\title{
Molecular identification of endophytic fungi associated with Coleus forskohlii (Willd.) Briq.
}

\author{
Grace Leena Crasta ${ }^{1,2 *}$ (D), Koteshwar Anandrao Raveesha ${ }^{1,3}$ \\ ${ }^{1}$ Center for Innovative Studies in Herbal Drug Technology, Department of Studies in Botany, University of Mysore, Mysuru, India. \\ ${ }^{2}$ Department of Botany, St. Josephs College (Autonomous), Bengaluru, India. \\ ${ }^{3}$ Department of Water and Health, Faculty of Life Sciences, JSS Academy of Higher Education and Research, Mysuru, India.
}

\begin{tabular}{l}
\hline ARTICLE INFO \\
\hline Article history: \\
Received on: June 06, 2021 \\
Accepted on: August 01, 2021 \\
Available online: November 10, 2021 \\
\hline
\end{tabular}

\section{Key words:}

Coleus forskohlii (Willd.)

Briq., Endophytic fungi, $18 \mathrm{~S}$

rRNA sequence, phylogenetic relationships

\begin{abstract}
Coleus forskohlii (Willd.) Briq. is a notable medicinal plant belonging to the family Lamiaceae. Understanding the diversity of endophytic fungi associated with this medicinally important plant species and screening them to yield bioactive compounds would be highly useful for the herbal drug industry. The present study was undertaken to isolate and identify the diversity of fungal endophytes associated with $C$. forskohlii (Willd.) Briq. The fungal endophytes were isolated following standard procedures and molecular identification was carried out by using the $18 \mathrm{~S}$ rRNA gene; the amplified regions were sequenced and submitted to NCBI, GenBank. A total of 85 endophytic fungi were isolated from 280 leaf segments. Molecular identification revealed 34 fungal genera. Among these, species of Cladosporium sp., Alternaria sp., Aspergillus niger, Aspergillus sp., Colletotrichum sp., Nigrospora oryzae, Penicillium sp., and Phyllosticta fallopiae were found to be predominant genera. The percentage occurrence of members of Ascomycota was the highest, with $96.47 \%$ distribution and Basidiomycota members were distributed the least, with $3.53 \%$. The study revealed the diversity of endophytic fungi associated with the leaves of $C$. forskohlii and the phylogenetic tree shows the relationships between the endophytic fungi.
\end{abstract}

\section{INTRODUCTION}

The phyllosphere and rhizosphere encompass a number of microorganisms. The microorganisms living inside the plant tissues are called endophytes. de Bary [1] introduced the term "endophytes" for the fungi residing inside the plant tissue and "epiphytes" for the fungi that reside on the surface of their host. Endophytic microorganisms such as bacteria, fungi, archaea, and protists live in the intercellular or intracellular regions of the plant tissues without causing any infectious symptoms to the plant. Such microorganisms exhibiting endophytic lifestyles play essential roles in the plant's growth, development, health and variation. Efficacious colonization of endophytes with the host plant depends upon many innate parameters such as plant genetic

\footnotetext{
*Corresponding Author

Grace Leena Crasta, Department of Botany, St. Josephs College (Autonomous), Bengaluru, India. E-mail: graceleena@ @sc.ac.in
}

constitution, tissue type, microflora, and species type, as well as the external abiotic factors $[2,3]$.

Almost all parts of the plants, for instance, the roots, stem, leaves, rhizome, inflorescence, seeds, etc. are occupied by endophytic fungi [4-6]. These endophytic fungi act as a reservoir for novel bioactive metabolites such as terpenes, phenolics, alkaloids, tannins, saponins, steroids, and quinones which aid as potential drugs against microbes, insects, cancers, and have many more curative roles. Thus, recently, the endophytes associated with the plants rather than the plants themselves have emerged as promising mines for novel drug discovery. Therefore, studies on endophytes are now of great significance, not only to encounter the microbial multiplicity but also to obtain novel chemical compounds that could be assuring drugs to treat several ailments $[7,8]$.

The Mint family, known as Lamiaceae or Labiatae, encompasses 245 genera and 7,886 species. The major genera under Lamiaceae are Salvia (986 sp.), Scutellaria (486 sp.), Plectranthus (325 sp.), 
Leucas (111 sp.), Pogostemon (94 sp.), Ocimum (66 sp.), Coleus (56 sp.), etc. Most of the members of Lamiaceae are herbaceous, but some are shrubs. They are known for their aromatic nature as they yield essential oils from almost all parts of the plant, and hence are extensively cultivated $[9,10]$.

Coleus forskohlii also known as Plectranthus barbatus or Coleus barbatus, vernacular names Coleus, Indian Coleus, false boldo, etc., is a medicinally important perennial plant which belongs to the Lamiaceae family and it grows to about $45-60 \mathrm{~cm}$ tall. It is found distributed in North, East, and Central Africa, Asia, and South America [11]. In India, $C$. forskohlii grows wild in the Himalayan region, from the Shimla hills extending through the Kumaon and Garhwal hills, at an altitudinal range of $600-2,300 \mathrm{~m}$; it is even found growing in the Parasnath hills (Bihar), in Gujarat and in the Western Ghats [12]. Coleus forskohlii is characterized by its intensely aromatic plant parts and has fasciculate tuberous roots. It has been used in traditional ayurvedic medicine for over 3,000 years and is mentioned in the ancient Sanskrit texts as a tonic for a healthy heart and lungs. It is used to treat heart diseases, abdominal colic, respiratory disorder, insomnia, convulsions, asthma, bronchitis, intestinal disorders, burning sensation, constipation, epilepsy, and angina. Coleus forskohlii is the only source of diterpenoid forskolin [13-16]. The roots of $C$. forskohlii are exploited for forskolin. Recently, the cultivation of $C$. forskohlii has gained importance and is spreading to different parts of the country, like Maharashtra, Gujarat, Madhya Pradesh, Andhra Pradesh, Tamil Nadu, and Karnataka, for its pharmaceutical value [17].

Like other plants, the members of Lamiaceae also inhabit a wide array of fungal endophytes. Fungal endophytes have been reported from various members, such as Coleus aromaticus, Ocimum sanctum, Ocimum basilicum, Leucas aspera, and Salvia miltiorrhiza [18-22].

The study pertaining to the identification and diversity of endophytic fungi of $C$. forskohlii and their medicinal properties is still an unexplored area of research. Therefore, an attempt was made to isolate and identify the fungal endophytes associated with C. forskohlii.

\section{MATERIALS AND METHODS}

\subsection{Sampling Site and Collection of Plant Material}

Coleus forskohlii leaves were collected from medicinal plant garden of St. Joseph's College Campus, Bengaluru (Latitude: $12^{\circ} 57^{\prime} 45.72^{\prime \prime} \mathrm{N}$; Longitude: $77^{\circ} 35^{\prime} 49.56^{\prime \prime} \mathrm{E}$; altitude above sea level: $900 \mathrm{~m} / 3,020 \mathrm{ft}$ ), Karnataka, India. The plant herbarium specimen was submitted to Foundation for Revitalisation of Local Health Traditions for identification and authentication, and the voucher number is FRLH Coll. No. 124372. About 3-4 months old, apparently healthy, mature, undamaged leaves were collected from the mature plants during the month of June 2019. The collected leaves (Fig. 1) were hermetically sealed in an aseptic plastic bag, carried to the laboratory, and were processed immediately.

\subsection{Isolation of Endophytic Fungi}

The samples were thoroughly washed under running tap water for 10 minutes to remove the debris and washed with sterile distilled water to wash off the epiphytic microbes. Three disks along the midvein and three disks from one or both sides of the midvein were cut into small disks of approximately $8 \times$ $8 \mathrm{~mm}$ size under aseptic conditions inside a laminar air flow cabinet. In total, 280 leaf disks were obtained from about 50 mature leaves. These bits of leaves were surface sterilized by immersing in $70 \%$ ethanol for 30 seconds, followed by $4 \%$ sodium hypochlorite for 30 seconds and dipping in $70 \%$ ethanol for 5-10 seconds and washed thoroughly (thrice) with sterilized distilled water [23]. Earlier studies have shown that the potato dextrose agar (PDA) medium was suitable to isolate fungal endophytes and hence PDA medium was chosen. After surface sterilization, the leaf material was dry blotted on sterile blotting paper and plated onto a $90 \mathrm{~mm}$ Petri plate containing PDA media supplemented with chloramphenicol $(200 \mathrm{mg} / \mathrm{l})$ to suppress the growth of bacteria [24]. Validation of surface sterilization was carried out by imprinting the surface sterilized plant tissue onto the PDA media. About five to six pieces of the plant material were carefully placed onto the PDA media. After 3-7 days of incubation with 12 hours of natural light and 12 hours of darkness, the mycelia emerging out from the plant material (Fig. 2) were subcultured onto fresh PDA media as and when the endophytic fungi were emerging, to obtain pure cultures (Figs. 3 and 4). Pure cultures of all the isolates were maintained by subculturing every month and also preserving the cultures using sterile distilled water [25]. The pure cultures were then subjected to molecular identification by using $18 \mathrm{~S}$ rRNA sequencing method.

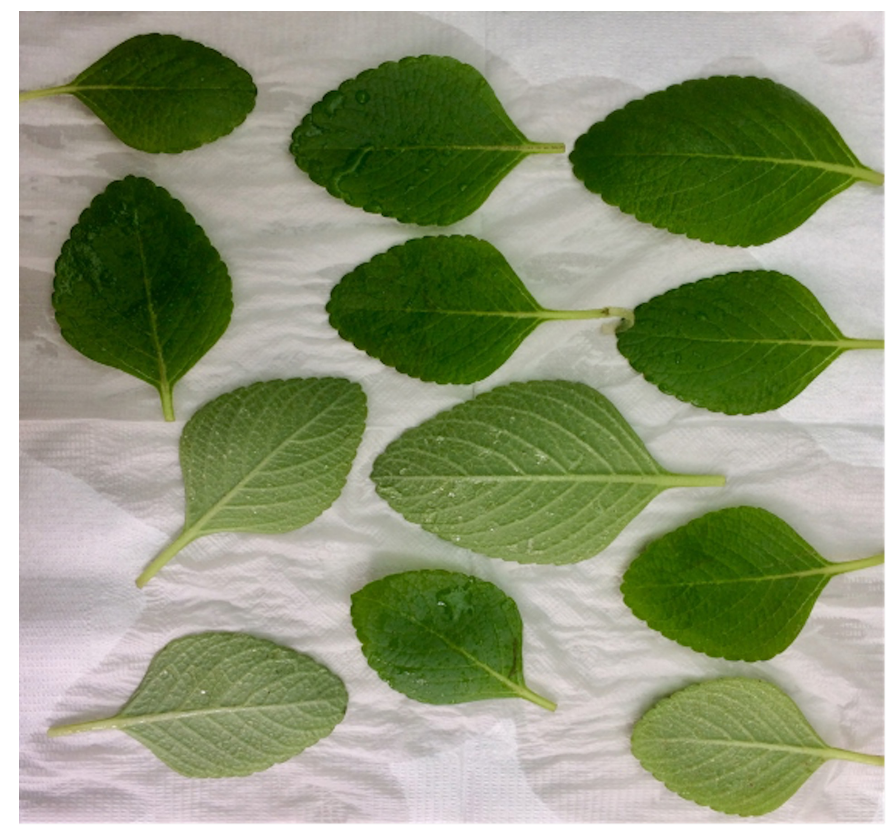

Figure 1: Healthy, fresh \& undamaged leaves of C. forskohlii (Willd.) Briq. 


\subsection{Identification of Fungal Endophytes}

The molecular identification of endophytic fungi was carried out using 18S rRNA gene sequencing method which is described below. The identification was confirmed by observing the morphological characteristics by conducting microscopic studies of the spores, hyphae, and colony.

\subsection{DNA Extraction and polymerase chain reaction (PCR) Amplification}

The DNA extraction was carried out by employing the cetyltrimethylammonium bromide (CTAB) method. $1 \mathrm{~g}$ of fresh fungal hyphae was obtained from 3 to 5 days old pure cultures grown on the PDA media. The fungal culture with CTAB extraction buffer was taken in a $2 \mathrm{ml}$ Eppendorf tube. The fungal sample was crushed in a chilled mortar pestle and volume was made up to $1 \mathrm{ml}$. To remove the RNA, DNAse-free RNAse A $(10 \mathrm{mg} / \mathrm{ml})$ was added to the tubes. The tubes were incubated at $37^{\circ} \mathrm{C}$ for 15 minutes then at $65^{\circ} \mathrm{C}$ for 30 minutes. The tubes were inverted at regular intervals. $1 \mathrm{ml}$ of phenol:chloroform:isoamylalcohol (25:24:1) was added to the tubes and centrifuged at $10,000 \mathrm{rpm}$ for 10 minutes. The upper aqueous layer from each tube was transferred to a fresh $2 \mathrm{ml}$ Eppendorf tube containing an equal volume of chloroform:isoamylalcohol (24:1). These tubes were centrifuged at 10,000 rpm for 10 minutes. The upper aqueous layer from each tube was transferred to a fresh $2 \mathrm{ml}$ Eppendorf tube containing an equal volume of $100 \%$ isopropyl alcohol and one-tenth volume $3 \mathrm{M}$ sodium acetate for DNA precipitation. The tubes were centrifuged at 10,000 rpm for 10 minutes after incubation period of 30 minutes at room temperature. The DNA pellet was washed with $1 \mathrm{ml}$ of

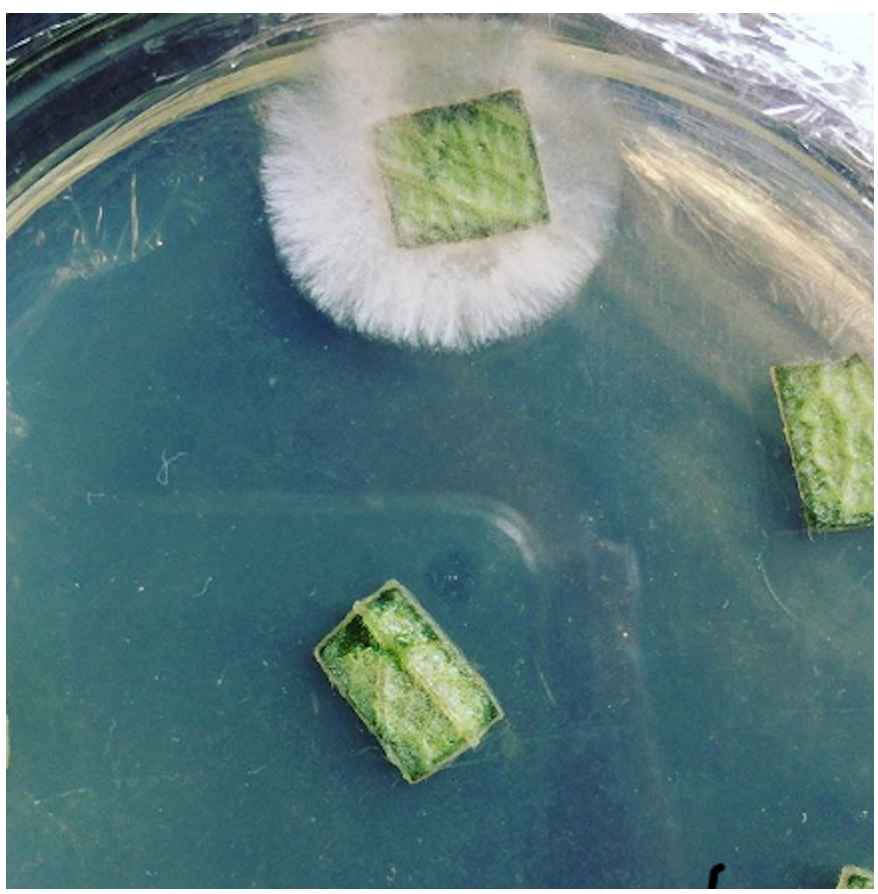

Figure 2: Fungal endophyte, A. flavus emerging from $C$. forskohlii leaf bit after 24 hours of incubation.
$70 \%$ ethanol by centrifuging at 5,000 rpm for 5 minutes and then air-dried. The DNA pellet was suspended in $1 \times$ Tris-EDTA buffer (Tris base $100 \mathrm{mM}$, ethylenediamine tetraacetic acid salt $1 \mathrm{mM}$ ). The pure DNA extracted was amplified by PCR using universal and degenerate primers. The PCR was carried out for 35 cycles with the following conditions: initial denaturation at $94^{\circ} \mathrm{C}$ for 5 minutes; denaturation at $94^{\circ} \mathrm{C}$ for 45 seconds; annealing at $57^{\circ} \mathrm{C}$ for 45 seconds; extension at $72^{\circ} \mathrm{C}$ for 2 minutes; and final extension at $72^{\circ} \mathrm{C}$ for 7 minutes. The PCR product was then subjected to gel electrophoresis to check the purity of the DNA, followed by which the sequence was analyzed using Sanger's dideoxy method to obtain a DNA sequence [26-28]. The forward and reverse DNA sequences of every sample were subjected to National Centre for Biotechnology Information Basic Local Alignment Search Tool (NCBI BLAST) algorithm for identification and the phylogenetic tree was also constructed using NCBI BLAST. All the identified $18 \mathrm{~S}$ rRNA sequences were submitted to the GenBank in fast-all format and accession numbers for the same were obtained.

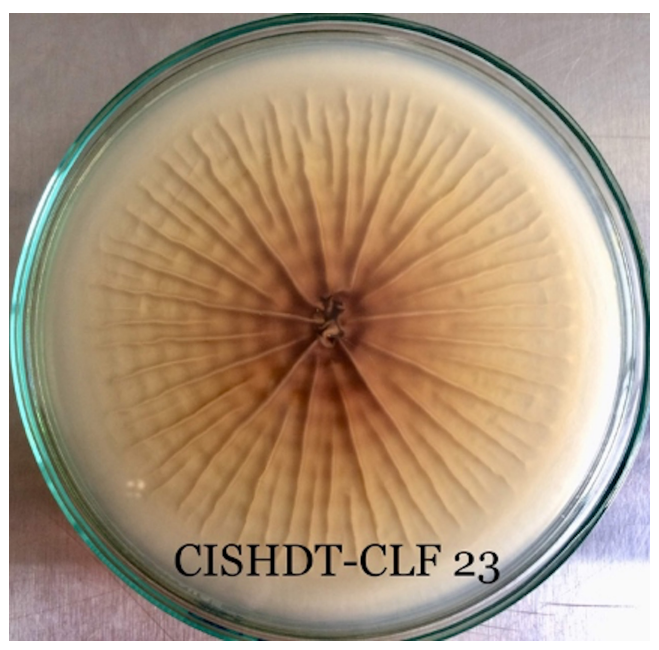

Figure 3: Lower surface view of fugal endophyte $A$. ochraceus.

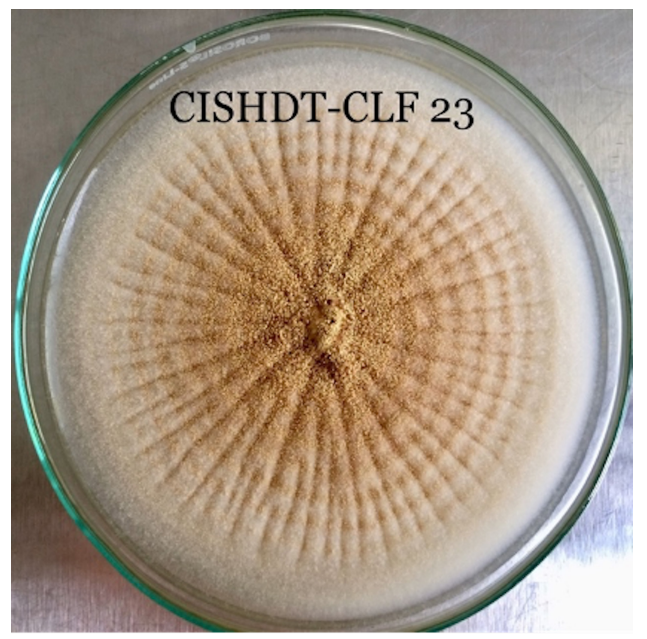

Figure 4: Upper surface view of fugal endophyte $A$. ochraceus. 


\subsection{Phylogenetic Affiliation}

A phylogenetic tree is essential to recognize the relationship between the fungal endophytes associated with $C$. forskohlii; hence, molecular evolutionary genetics analysis (MEGA X) was used for depicting the same [29].

\subsection{Statistical Analysis}

In order to understand the results, colonization frequency, endophyte isolation rate, and relative percentage occurrence were calculated using the below-mentioned formula.

\subsubsection{Colonization frequency $(C F)$}

The CF\% of the fungal endophytes was calculated using the following formula given by Hata and Futai (1995) [30]:

$$
\mathrm{CF}(\%)=\frac{\begin{array}{c}
\text { Number of segments colonized by each } \\
\text { endophyte }
\end{array}}{\text { Total number of segments examined }} \times 100
$$

\subsubsection{Endophytic isolation rate (EIR)}

The EIR was calculated using the following formula [31]:

$$
\text { EIR }=\frac{\text { Number of isolates obtained from plant segments }}{\text { Total number of segments incubated }}
$$

\subsubsection{Relative percentage occurrence (RPO)}

The RPO of different fungal groups was calculated using the following formula [32]:

$$
\begin{aligned}
& \text { Number of segments colonized by a group } \\
& \text { RPO }(\%)=\frac{\text { of fungi }}{\text { Total number of segments colonized by all }} \times 100
\end{aligned}
$$

\section{RESULTS}

\subsection{Isolation and Identification of Fugal Endophytes}

A total of 85 endophytic fungi were isolated from 280 bits of leaves of $C$. forskohlii. Molecular identification using 18S rRNA sequencing revealed 34 genera of fungal endophytes, which are as follows: Albifimbria verrucaria, Alternaria alternata, Alternaria sp., Aspergillus flavus, Aspergillus niger, Aspergillus ochraceus, Aspergillus sp., Aspergillus versicolor, Byssochlamys spectabilis, Cercospora sojina, Chaetomium globosum, Cladosporium sp., Cochliobolus sp., Colletotrichum coccodes, Colletotrichum sp., Colletotrichum truncatum, Coprinopsis atramentaria, Davidiellaceae sp., Diaporthe sp., Didymosphaeria variabile, Hebeloma angustilamellatum, Lecanicillium sp., Nigrospora oryzae, Ochraceocephala foeniculi, Penicillium citrinum, Penicillium limosum, Penicillium oxalicum, Penicillium sp., Phyllosticta fallopiae, Phyllosticta neopyrolae, Psathyrella gracilis, Pseudocercospora fuligena, Pseudocercospora pallida, and Scopulariopsis brevicaulis. The frequency of occurrence of these 34 endophytic fungi is shown in Figure 5. Figures 6-8 show the morphology of the colonies of different fungi that were isolated. Among the 85 endophytic fungi, 83 belonged to Ascomycota and 2 belonged to Basidiomycota. To understand the phylogenetic affiliations between the endophytic fungi, a phylogenetic tree was constructed using MEGA X software. The DNA sequences were submitted to GenBank and the accession numbers were obtained for the same.

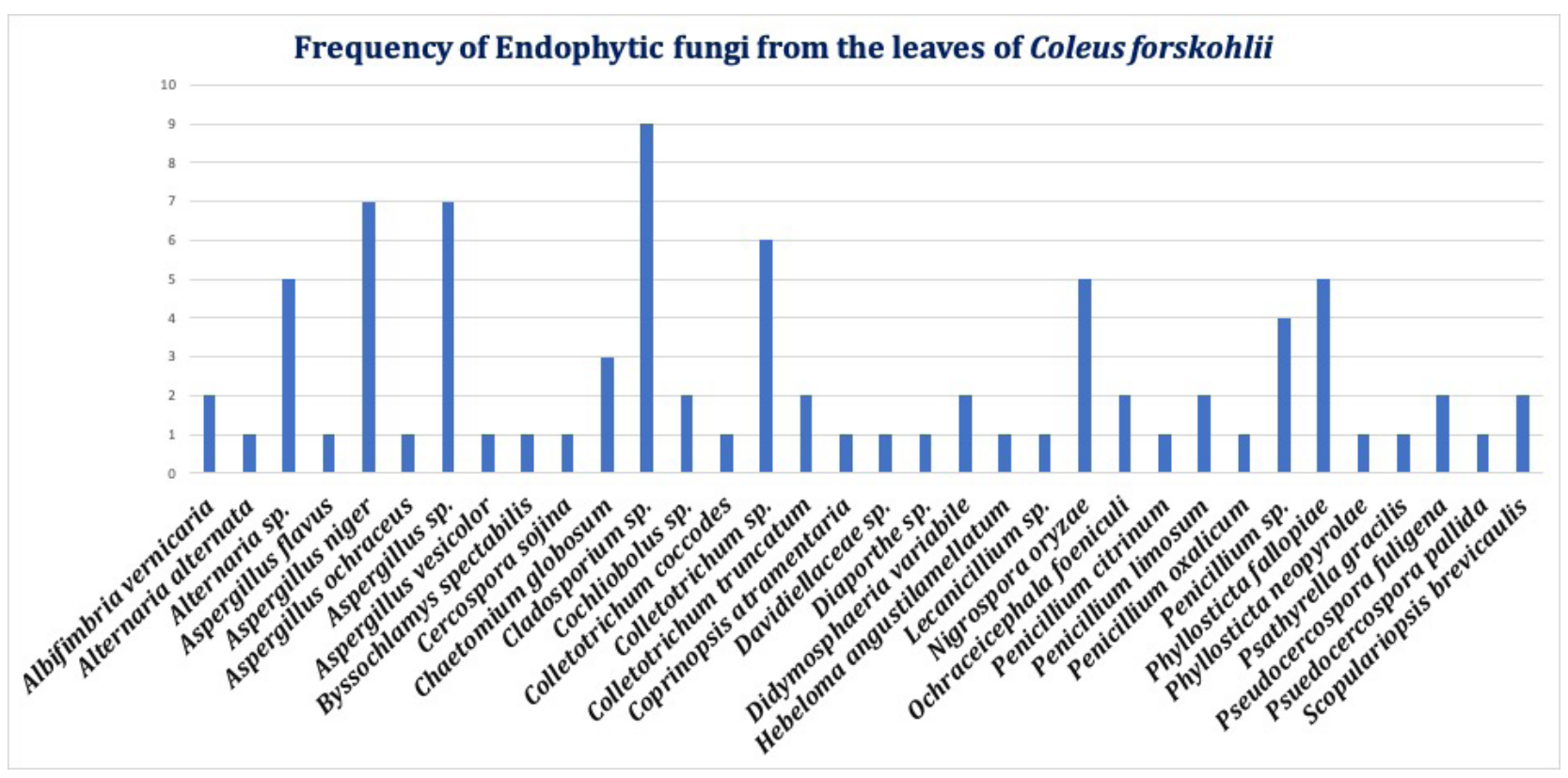

Figure 5: Frequency of occurrence of fungal endophytes of C. forskohlii. 


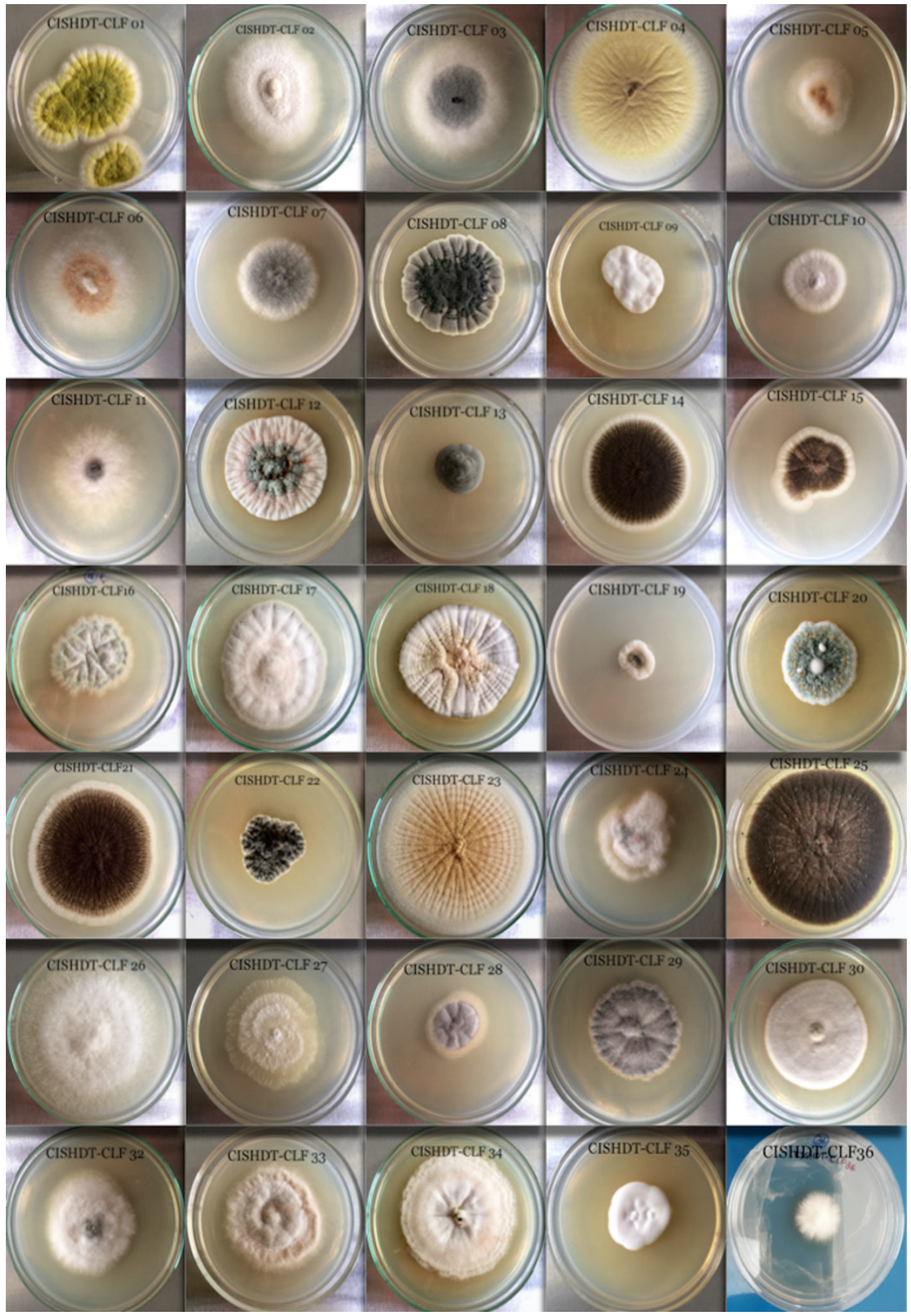

Figure 6: Pure cultures of the fungal endophytes isolated from $C$. forskohlii CISHDT-CLF01-CISHDT-CLF36. 


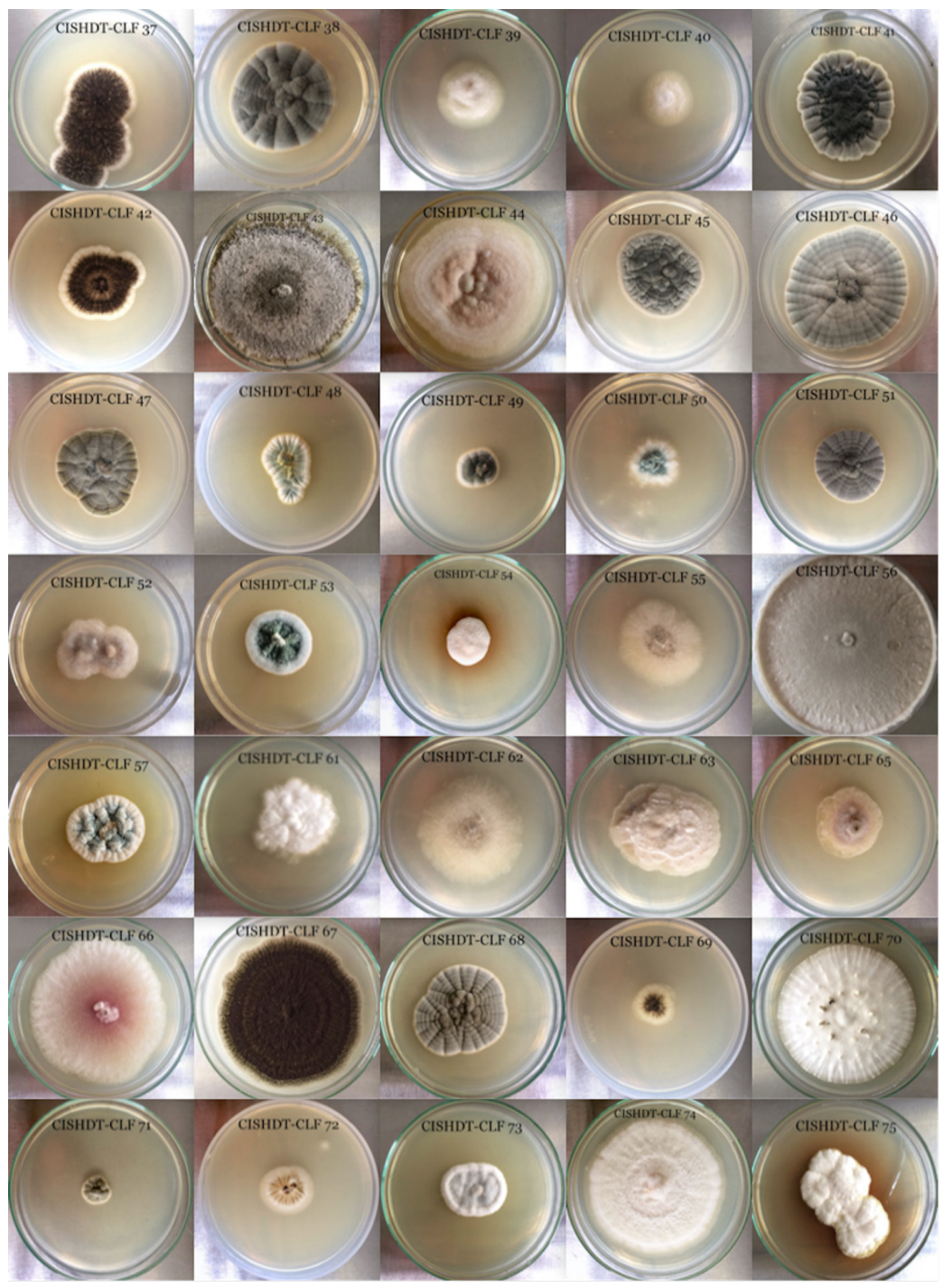

Figure 7: Pure cultures of the fungal endophytes isolated from C. forskohlii CISHDTCLF37- CISHDT-CLF75.

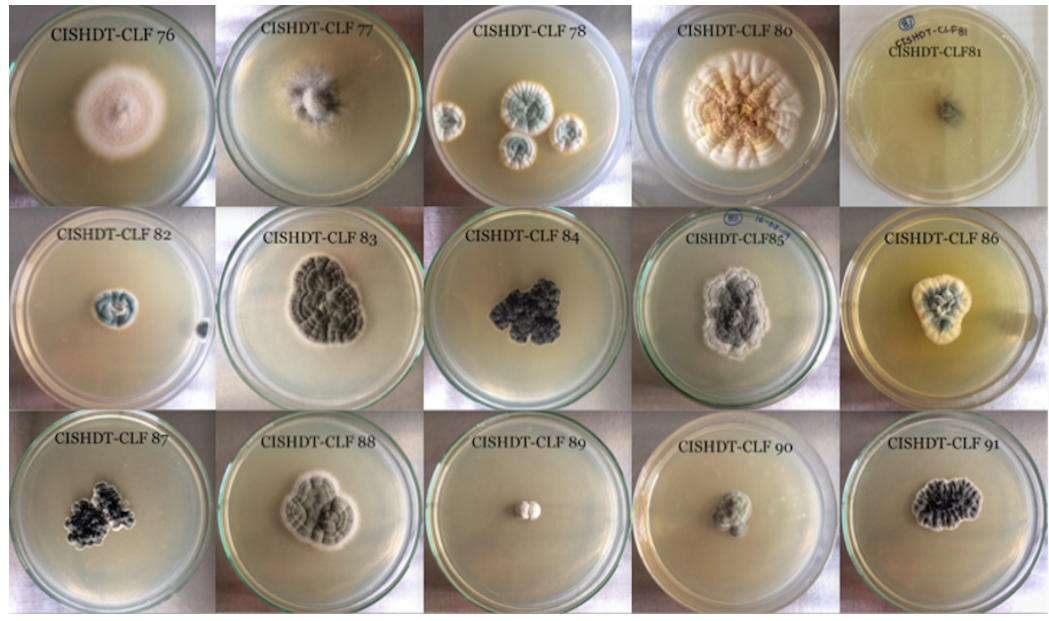

Figure 8: Pure cultures of the fungal endophytes isolated from C. forskohlii CISHDT-CLF76CISHDT-CLF91. 


\subsection{Phylogenetic Affiliation}

The phylogenetic affiliation of fungal endophytes associated with C. forskohlii is shown in Figure 9.

\subsection{Statistical Analysis}

\subsubsection{Colonization frequency $(C F)$}

The $\mathrm{CF} \%$ of the fungal endophytes was calculated using the following formula given by Hata and Futai (1995):

$$
\begin{aligned}
\mathrm{CF}(\%) & =(85 / 280) \times 100 \\
& =30.35 \%
\end{aligned}
$$

\subsubsection{Endophytic isolation rate (EIR)}

The EIR was calculated as follows:

$$
\begin{aligned}
\text { EIR } & =85 / 280 \\
& =0.303
\end{aligned}
$$

\subsubsection{Relative percentage occurrence (RPO)}

The RPO of different fungal groups were calculated as follows:

RPO of Ascomycota group ( $\%)=96.47 \%$

RPO of Basidiomycota group $(\%)=3.53 \%$

\section{DISCUSSION}

As plants evolved to the terrestrial locale during the Ordovician period (470 million years), their interaction and association with the microbial communities have occurred instantaneously. The microorganisms have evolved along with the plants to shape their new niches into the host plant tissues to benefit themselves. At the same time, this colonization has benefitted the plant's growth, fitness, and adaptability to nature [33]. The association of fungal endophytes with plants has been well understood in most plant groups, from the primitive groups like lichens and mosses, as well as some of the angiosperms [34,35]. The colonization of endophytic fungi with the host plant could enhance the ability of the host plant to survive in nature by secreting some bioactive compounds which could help the host plant defend itself against a wide range of pathogens and other abiotic stresses [36-38].

Although understanding the different kinds of secondary metabolites produced by the host plant and the endophytic fungi is essential, it is also necessary for us to understand the diversity and phylogenetic relationships of the endophytic fungi associated with the host plant as this will help us to fish out some host-specific fungal endophytes and their bioactive molecules. Studies on $C$. forskohlii (Willd.) Briq. have shown that endophytes regulate and enhance the production of secondary metabolites such as forskolin [39], but understanding the diversity of endophytes associated with $C$. forskohlii is least understood; therefore, the results of the present study have elaborated on the diversity of the fungal endophytes associated with $C$. forskohlii and also revealed their phylogenetic relations.

In the present study, 85 endophytic fungi were isolated from 280 leaf segments of $C$. forskohlii. Molecular identification using the $18 \mathrm{~S}$ rRNA gene sequencing has revealed 34 different genera of endophytic fungi namely $A$. verrucaria, A. alternata, Alternaria sp., A. flavus, A. niger, A. ochraceus, Aspergillus sp., A. versicolor, B. spectabilis, C. sojina, C. globosum, Cladosporium sp., Cochliobolus sp., C. coccodes, Colletotrichum sp., $C$. truncatum, C. atramentaria, Davidiellaceae sp., Diaporthe sp., D. variabile, $H$. angustilamellatum, Lecanicillium sp., N. oryzae, $O$. foeniculi, P. citrinum, P. limosum, $P$. oxalicum, Penicillium sp., $P$. fallopiae, $P$. neopyrolae, $P$. gracilis, $P$. fuligena, $P$. pallida, and $S$. brevicaulis which showed $>97.1 \%$ match with the existing fungi in the NCBI database (Table 1). This is the first study to report the diversity of fungal endophytes from $C$. forskohlii except for one study which has reported the existence of endophytic fungiRhizactonia bataticola - and a sterile hypha [40]. Although

\begin{tabular}{|c|c|c|c|c|}
\hline SI. no. & $\begin{array}{c}\text { Isolate ID } \\
\text { (GenBank accession no.) }\end{array}$ & Endophytic fungal species & GenBank accession number & Percentage match (\%) \\
\hline 1 & $\begin{array}{l}\text { Centre for Innovative Studies } \\
\text { in Herbal Drug Technology } \\
\text { - Coleus Leaf Fungi (CISHDT- } \\
\text { CLF 01) (MT740749) }\end{array}$ & A. flavus & СР044617.1 & 99.82 \\
\hline 2 & CISHDT-CLF 02 (MT764264) & D. variabile & NG_064914.1 & 99.40 \\
\hline 3 & CISHDT-CLF 03 (MT749388) & N. oryzae & AB220233.1 & 100 \\
\hline 4 & CISHDT-CLF 04 (MT749387) & B. spectabilis & KT031992.1 & 98.10 \\
\hline 5 & CISHDT-CLF 05 (MT749670) & P. gracilis & DQ851582.1 & 99.23 \\
\hline 6 & CISHDT-CLF 06 (MT764263) & H. angustilamellatum & NG_070875.1 & 98.56 \\
\hline 7 & CISHDT-CLF 07 (MT750014) & C. coccodes & MF376146.1 & 99.67 \\
\hline 8 & CISHDT-CLF 08 (MT750219) & P. fuligena & GU214675.1 & 98.70 \\
\hline 9 & CISHDT-CLF 09 (MT763960) & Aspergillus sp. & MF185177.1 & 99.48 \\
\hline 10 & CISHDT-CLF 10 (MT750290) & A. niger & MN420840.1 & 99.52 \\
\hline
\end{tabular}
many fungi reported are commonly isolated ones, with reference to "A worldwide list of endophytic fungi with notes on ecology

Table 1: Maximum nucleotide identity matches for 85 endophytic fungi based on 18S rRNA sequencing using the BLAST analysis. 


\begin{tabular}{|c|c|c|c|c|}
\hline SI. no. & $\begin{array}{c}\text { Isolate ID } \\
\text { (GenBank accession no.) }\end{array}$ & Endophytic fungal species & GenBank accession number & Percentage match (\%) \\
\hline 11 & CISHDT-CLF 11 (MT750289) & N. oryzae & AB220233.1 & 99.87 \\
\hline 12 & CISHDT-CLF 12 (MT762337) & A. versicolor & AB002064.1 & 99.21 \\
\hline 13 & CISHDT-CLF 13 (MT762297) & P. fuligena & GU214675.1 & 100 \\
\hline 14 & CISHDT-CLF 14 (MT762340) & C. truncatum & AJ301945.1 & 99.88 \\
\hline 15 & CISHDT-CLF 15 (MT762341) & A. niger & MG889595.1 & 99.61 \\
\hline 16 & CISHDT-CLF 16 (MT762356) & Aspergillus sp. & KP872521.1 & 99.88 \\
\hline 17 & CISHDT-CLF 17 (MT762359) & Cochliobolus sp. & KX852423.1 & 99.94 \\
\hline 18 & CISHDT-CLF 18 (MT762367) & C. sojina & СР036216.1 & 100 \\
\hline 19 & $\begin{array}{l}\text { CISHDT-CLF } 19 \\
\text { (MT801133) }\end{array}$ & Cochliobolus sp. & KX852423.1 & 99.94 \\
\hline 20 & CISHDT-CLF 20 (MT762369) & Penicillium sp. & KP872503.1 & 98.84 \\
\hline 21 & CISHDT-CLF 21 (MT762399) & A. niger & MN420840.1 & 99.80 \\
\hline 22 & CISHDT-CLF 22 (MT762400) & P. fallopiae & NG_064828.1 & 99.76 \\
\hline 23 & CISHDT-CLF 23 (MT762907) & A. ochraceus & AF548065.1 & 100 \\
\hline 24 & CISHDT-CLF 24 (MT762814) & Colletotrichum sp. & $\mathrm{AB} 076801.1$ & 99.88 \\
\hline 25 & CISHDT-CLF 25 (MT762908) & N. oryzae & AB220233.1 & 99.93 \\
\hline 26 & CISHDT-CLF 26 (MT762909) & N. oryzae & MH014997.1 & 99.80 \\
\hline 27 & CISHDT-CLF 27 (MT763199) & Diaporthe sp. & MK299422.1 & 100 \\
\hline 28 & CISHDT-CLF 28 (MT776313) & O.foeniculi & MN516743.1 & 97.10 \\
\hline 29 & CISHDT-CLF 29 (MT776176) & O. foeniculi & MN516743.1 & 99.58 \\
\hline 30 & CISHDT-CLF 30 (MT763390) & Alternaria sp. & KT192438.1 & 99.94 \\
\hline 31 & CISHDT-CLF 32 (MT763957) & Colletotrichum sp. & MK299420.1 & 99.64 \\
\hline 32 & CISHDT-CLF 33 (MT763958) & Alternaria sp. & KT192438.1 & 99.35 \\
\hline 33 & CISHDT-CLF 34 (MT763959) & Lecanicillium $\mathrm{sp}$. & LT992875.1 & 99.88 \\
\hline 34 & CISHDT-CLF 35 (MT763960) & Aspergillus sp. & MF185177.1 & 99.48 \\
\hline 35 & CISHDT-CLF 36 (MT763961) & C. globosum & JQ964323.1 & 99.47 \\
\hline 36 & CISHDT-CLF 37 (MT763962) & A. niger & MN420840.1 & 99.93 \\
\hline 37 & CISHDT-CLF 38 (MT767108) & Cladosporium sp. & KP997210.1 & 99.76 \\
\hline 38 & CISHDT-CLF 39 (MT767111) & Colletotrichum sp. & AB076801.1 & 99.41 \\
\hline 39 & CISHDT-CLF 40 (MT767107) & Colletotrichum sp. & AB076801.1 & 99.81 \\
\hline 40 & CISHDT-CLF 41 (MT770956) & P. fallopiae & NG_064828.1 & 99.16 \\
\hline 41 & CISHDT-CLF 42 (MT767113) & A. niger & MG889595.1 & 99.93 \\
\hline 42 & CISHDT-CLF 43 (MT767172) & N. oryzae & AB220233.1 & 99.74 \\
\hline 43 & CISHDT-CLF 44 (MT767173) & C. atramentaria & DQ115781.1 & 99.35 \\
\hline 44 & CISHDT-CLF 45 (MT767174) & Cladosporium sp. & LT860211.1 & 99.87 \\
\hline 45 & CISHDT-CLF 46 (MT767175) & Cladosporium sp. & MH07202.1 & 99.82 \\
\hline 46 & CISHDT-CLF 47 (MT770925) & Cladosporium sp. & МH015002.1 & 99.80 \\
\hline 47 & CISHDT-CLF 48 (MT770926) & P. limosum & NG_062729.1 & 98.89 \\
\hline 48 & CISHDT-CLF 49 (MT770927) & Cladosporium sp. & MH047202.1 & 99.88 \\
\hline 49 & CISHDT-CLF 50 (MT770928) & Aspergillus sp. & MN326853.1 & 100 \\
\hline 50 & CISHDT-CLF 51 (MT770929) & Cladosporium sp. & KP997210.1 & 99.67 \\
\hline 51 & CISHDT-CLF 52 (MT770930) & A. alternata & HM165489.1 & 99.94 \\
\hline
\end{tabular}




\begin{tabular}{|c|c|c|c|c|}
\hline Sl. no. & $\begin{array}{c}\text { Isolate ID } \\
\text { (GenBank accession no.) }\end{array}$ & Endophytic fungal species & GenBank accession number & Percentage match (\%) \\
\hline 52 & CISHDT-CLF 53 (MT770931) & Penicillium sp. & KP256500.1 & 99.38 \\
\hline 53 & CISHDT-CLF 54 (MT770948) & Aspergillus sp. & EU853156.1 & 99.55 \\
\hline 54 & CISHDT-CLF 55 (MT770931) & C. globosum & JQ964323.1 & 99.54 \\
\hline 55 & CISHDT-CLF 56 (MT770933) & C. truncatum & AJ301937.1 & 97.45 \\
\hline 56 & CISHDT-CLF 57 (MT770934) & P. citrinum & LC127087.1 & 99.93 \\
\hline 57 & CISHDT-CLF 61 (MT770935) & S. brevicaulis & KJ443074.1 & 99.60 \\
\hline 58 & CISHDT-CLF 62 (MT770936) & C. globosum & JQ964323.1 & 98.69 \\
\hline 59 & CISHDT-CLF 63 (MT770937) & Alternaria sp. & KT192438.1 & 99.30 \\
\hline 60 & CISHDT-CLF 65 (MT770938) & Alternaria sp. & KT192438.1 & 99.94 \\
\hline 61 & CISHDT-CLF 66 (MT770939) & Colletotrichum sp. & $\mathrm{AB} 076801.1$ & 99.20 \\
\hline 62 & $\begin{array}{l}\text { CISHDT-CLF } 67 \\
\text { (MT770940) }\end{array}$ & Aspergillus sp. & EU853156.1 & 100 \\
\hline 63 & CISHDT-CLF 68 (MT770941) & Davidiellaceae sp. & GU250343.1 & 97.12 \\
\hline 64 & CISHDT-CLF 69 (MT770942) & A. niger & MN420840.1 & 99.87 \\
\hline 65 & CISHDT-CLF 70 (MT770943) & A. verrucaria & NG_061023.1 & 99.61 \\
\hline 66 & CISHDT-CLF 71 (MT770944) & Cladosporium $\mathrm{sp}$. & MH015002.1 & 99.87 \\
\hline 67 & CISHDT-CLF 72 (MT770945) & A. niger & MG889595.1 & 99.74 \\
\hline 68 & CISHDT-CLF 73 (MT770946) & Penicillium sp. & KC143067.1 & 99.27 \\
\hline 69 & CISHDT-CLF 74 (MT770947) & Colletotrichum sp. & AB076801.1 & 99.21 \\
\hline 70 & CISHDT-CLF 75 (MT770948) & Aspergillus sp. & EU853156.1 & 99.55 \\
\hline 71 & CISHDT-CLF 76 (MT770949) & D. variabile & MK123327.1 & 99.78 \\
\hline 72 & CISHDT-CLF 77 (MT770950) & Colletotrichum sp. & MK299420.1 & 99.46 \\
\hline 73 & CISHDT-CLF 78 (MT770951) & P. oxalicum & KF152942.1 & 99.75 \\
\hline 74 & CISHDT-CLF 80 (MT770952) & A. verrucaria & NG_061023.1 & 98.27 \\
\hline 75 & CISHDT-CLF 81 (MT770953) & Alternaria sp. & KT192438.1 & 99.33 \\
\hline 76 & CISHDT-CLF 82 (MT770954) & P. limosum & NG_062729.1 & 99.61 \\
\hline 77 & CISHDT-CLF 83 (MT770955) & Cladosporium sp. & MH047202.1 & 99.76 \\
\hline 78 & CISHDT-CLF 84 (MT770956) & P. fallopiae & NG_064828.1 & 99.16 \\
\hline 79 & CISHDT-CLF 85 (MT770957) & P. fallopiae & NG_064828.1 & 100 \\
\hline 80 & CISHDT-CLF 86 (MT770958) & Penicillium sp. & KP872503.1 & 99.94 \\
\hline 81 & CISHDT-CLF 87 (MT770959) & P. neopyrolae & NG_064830.1 & 99.58 \\
\hline 82 & CISHDT-CLF 88 (MT770960) & Cladosporium sp. & MH047202.1 & 99.74 \\
\hline 83 & CISHDT-CLF 89 (MT770961) & P. pallida & GU214680.1 & 99.94 \\
\hline 84 & CISHDT-CLF 90 (MT770962) & S. brevicaulis & KJ443074.1 & 100 \\
\hline 85 & CISHDT-CLF 91 (MT770963) & P. fallopiae & NG_064828.1 & 99.80 \\
\hline
\end{tabular}

and diversity" [41], A. verrucaria, C. sojina, C. truncatum, $H$. angustilamellatum, $O$. foeniculi, $P$. fallopiae, $P$. neopyrolae, $P$. gracilis, $P$. fuligena, and $P$. pallida are among the rarely/not very commonly reported endophytic fungi which are newly reported in this study.

Among the 34 genera, the frequency of occurrence of Cladosporium sp. was found to be highest, and the other predominant genera were found to be Alternaria sp., A. niger, Aspergillus sp., Colletotrichum sp., N. oryzae, Penicillium sp., and P. fallopiae (Fig. 5). Colonization frequency of the endophytic fungi associated with the leaves of $C$. forskohlii (Willd.) Briq. was found to be $30.35 \%$ and the endophyte isolation rate from leaf tissue was found to be 0.303 . Many studies have revealed ascomycetes to be highest associated fungal endophytic group $[42,43]$, likewise the fungal group highest associated with the leaves of $C$. forskohlii was also found to be Ascomycota with $96.47 \%$ RPO and Basidiomycota to be the least associated with $3.53 \%$ RPO. The percentage occurrence of members of Ascomycota was the highest, with $96.47 \%$ distribution and Basidiomycota members were distributed the least, with $3.53 \%$. 


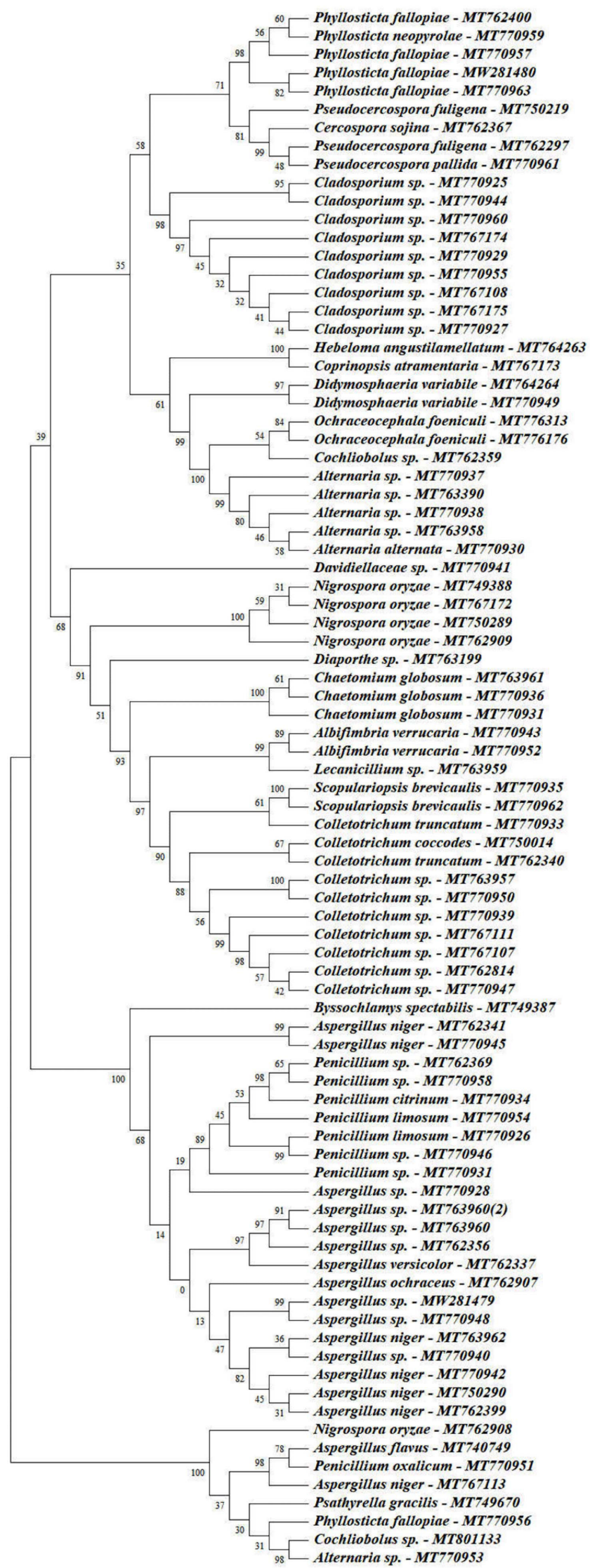

Figure 9: Phylogenetic affiliation of fungal endophytes from C. forskohlii.

\section{CONCLUSION}

Coleus forskohlii is an essential pharmaceutical crop which is a rich source of secondary metabolites. About 68 medicinally important compounds are isolated from different parts of the plant, among which forskolin is the principal compound which is found only in C. forskohlii [44]. The root tubers are the main source of forskolin. Harvesting of tubers results in the death of plants, thus harvesting of forskolin is a plant destructive harvest process. Thus, there is a need for alternative non-destructive, eco-friendly process for obtaining forskolin.

Fungal endophytes associated with medicinal plants represent an abundant and dependable source of novel bioactive compounds. Fungal endophytes of C. forskohlii are unexplored. Understanding the diversity of fungal endophytes associated with $C$. forskohlii is the first step toward exploitation of these endophytes to obtain different medicinally active compounds. The present investigation is first report of the diversity of fungal endophytes (34) associated with $C$. forskohlii leading to the future lines of research of screening these frequently occurring endophytes for medicinally active bioactive compounds.

\section{ACKNOWLEDGMENT}

The authors wish to extent their sincere gratitude to Dr. K.A. Raveesha for sharing his expertise, providing guidance, and support.

\section{AUTHOR CONTRIBUTIONS}

All authors made substantial contributions to conception and design, acquisition of data, or analysis and interpretation of data; took part in drafting the article or revising it critically for important intellectual content; agreed to submit to the current journal; gave final approval of the version to be published; and agree to be accountable for all aspects of the work. All the authors are eligible to be an author as per the international committee of medical journal editors (ICMJE) requirements/guidelines.

\section{FUNDING}

There is no funding to report.

\section{CONFLICT OF INTEREST}

The authors have declared no conflicts of interest.

\section{ETHICAL APPROVALS}

This study does not involve experiments on animals or human subjects.

\section{REFERENCES}

1. Bary A. Morphologie und physiologie der pilze, flechten und myxomyceten. In Engelmann (ed.). Holfmeister's handbook of physiological botany, Leipzig, Germany, 1866, vol. 2.

2. Kaul S, Gupta S, Ahmed M, Dhar MK. Endophytic fungi from medicinal plants: a treasure hunt for bioactive metabolites. Phytochem Rev 2012;11(4):487-505.

3. Hardoim PR, Van Overbeek LS, Berg G, Pirttilä AM, Compant S, Campisano A. The hidden world within plants: ecological and 
evolutionary considerations for defining functioning of microbial endophytes. Microbiol Mol Biol Rev 2015;79(3):293-320.

4. Nalini MS, Sunayana N, Prakash HS. Endophytic fungal diversity in medicinal plants of Western Ghats, Int J Biodivers 2014;2014:1-9.

5. Bezerra JD, Nascimento CC, Barbosa RD, da Silva DC, Svedese VM, Silva-Nogueira EB, et al. Endophytic fungi from medicinal plant Bauhinia forficata: diversity and biotechnological potential. Braz J Microbiol 2015;46(1):49-57.

6. Chutulo EC, Chalannavar RK. Endophytic mycoflora and their bioactive compounds from Azadirachta indica: a comprehensive review. J Fungi 2018;4(2):42.

7. Gond SK, Verma VC, Mishra A, Kumar A, Kharwar RN. 15 role of fungal endophytes in plant protection. In: Arya A, Perrello AE (eds.). Management of fungal plant pathogens, Oxfordshire, UK, vol. 15, pp 183-91, 2010.

8. Gouda S, Das G, Sen SK, Shin HS, Patra JK. Endophytes: a treasure house of bioactive compounds of medicinal importance. Front Microbiol 2016;7:1538.

9. Gamble JS, Fischer CE. Flora of the presidency of Madras. West, Newman and Adlard, London, UK, 1915.

10. Raja RR. Medicinally potential plants of Labiatae (Lamiaceae) family: an overview. Res J Med Plant 2012;6(3):203-13.

11. Lukhoba CW, Simmonds MS, Paton AJ. Plectranthus: a review of ethnobotanical uses. J Ethnopharmacol 2006;103(1):1-24.

12. Das A, Kamal S, Shakil NA, Sherameti I, Oelmüller R, Dua M, et al. The root endophyte fungus Piriformospora indica leads to early flowering, higher biomass and altered secondary metabolites of the medicinal plant, Coleus forskohlii. Plant Signal Behav 2012;7(1):103-12.

13. Ammon HP, Müller AB. Forskolin: from an ayurvedic remedy to a modern agent. Planta Medi 1985;51(06):473-7.

14. Kavitha C, Vadivel E, Rajamani K. Evaluation of Coleus forskohlii genotypes for bio chemical characters. Res J Med Plant 2009;3(2):75-9.

15. Ma C, Zou L, Xia Y, Tu Y, Xue D, Yang Y, et al. Extracts of Coleus forskohlii relieves cough and asthma symptoms via modulating inflammation and the extracellular matrix. $J$ Cell Biochem 2019;120(6):9648-55.

16. Rolta R, Kumar V, Sourirajan A, Upadhyay NK, Dev K. Phytocompounds of three medicinal plants (Juniperus communis, Urtica dioica and Coleus forskohlii) of north west Himalayas increases the potency of antibacterial and antifungal antibiotics. Plant Arch 2020;20(2):481-9.

17. Balasubramanian V, Suresh J, Srinivasan R, Prabhu M, Manikandan E, Nandha VG. Evaluation of soil characteristics and yield variation of coleus (Coleus forskohlii) in different agro climatic zones of Tamil Nadu. Int J Conserv Sci 2020;8(4):2841-5.

18. Krishnamurthy YL, Naik SB, Jayaram S. Fungal communities in herbaceous medicinal plants from the Malnad region, Southern India. Microb Environ 2008;23(1):24-8.

19. Rajagopal K, Kalavathy S, Kokila S, Karthikeyan S, Kathiravan G, Prasad R, et al. Diversity of fungal endophytes in few medicinal herbs of South India. Asian J Exp Biol Sci 2010;1(2):415-8.

20. Amirita A, Sindhu P, Swetha J, Vasanthi NS, Kannan KP. Enumeration of endophytic fungi from medicinal plants and screening of extracellular enzymes. World J Sci Technol 2012;2(2):13-9.

21. Lou J, Fu L, Luo R, Wang X, Luo H, Zhou L. Endophytic fungi from medicinal herb Salvia miltiorrhiza Bunge and their antimicrobial activity. African J Microbiol Res 2013;7(47):5343-9.

22. Chowdhary K, Kaushik N. Fungal endophyte diversity and bioactivity in the Indian medicinal plant Ocimum sanctum Linn. PLoS One 2015;10(11):e0141444.

23. Suryanarayanan TS, Murali TS, Venkatesan G. Occurrence and distribution of fungal endophytes in tropical forests across a rainfall gradient. Can J Bot 2002;80(8):818-26.

24. Srivastava AP, Anandrao RK. Antimicrobial potential of fungal endophytes isolated from leaves of Prosopis juliflora (SW.) DC. an important weed. Int J Pharm Pharm Sci 2015;7:128-36.
25. Hallmann J, Quadt-Hallmann A, Mahaffee WF, Kloepper JW. Bacterial endophytes in agricultural crops. Can J Microbiol 1997;43(10):895-914.

26. Sanger F, Nicklen S, Coulson AR. DNA sequencing with chainterminating inhibitors. Proc Nat Acad Sci USA 1977;74(12):5463-7.

27. Cubero OF, Crespo AN, Fatehi J, Bridge PD. DNA extraction and PCR amplification method suitable for fresh, herbarium-stored, lichenized, and other fungi. Plant Syst Evol 1999;216(3):243-9.

28. Gontia-Mishra I, Tripathi N, Tiwari S. A simple and rapid DNA extraction protocol for filamentous fungi efficient for molecular studies. Indian J Biotechnol 2014;13(4): 536-9.

29. Kumar S, Stecher G, Li M, Knyaz C, Tamura K. MEGA X: molecular evolutionary genetics analysis across computing platforms. Mol Biol Evol 2018;35(6):1547-9.

30. Hata K, Futai K. Endophytic fungi associated with healthy pine needles and needles infested by the pine needle gall midge, Thecodiplosis japonensis. Can J Bot 1995;73(3):384-90.

31. Petrini O, Stone J, Carroll FE. Endophytic fungi in evergreen shrubs in western Oregon: a preliminary study. Can J Bot 1982;60(6):789-96.

32. Suryanarayanan TS, Thennarasan S. Temporal variation in endophyte assemblages of Plumeria rubra leaves. Fungal Divers 2004;15:197-204.

33. Hassani MA, Durán P, Hacquard S. Microbial interactions within the plant holobiont. Microbiome 2018;6(1):1-7.

34. Arnold AE, Henk DA, Eells RL, Lutzoni F, Vilgalys R. Diversity and phylogenetic affinities of foliar fungal endophytes in loblolly pine inferred by culturing and environmental PCR. Mycologia 2007;99(2):185-206.

35. U'Ren JM, Lutzoni F, Miadlikowska J, Arnold AE. Community analysis reveals close affinities between endophytic and endolichenic fungi in mosses and lichens. Microb Ecol 2010;60(2):340-53.

36. Sreekanth D, Sushim GK, Syed A, Khan BM, Ahmad A. Molecular and morphological characterization of a taxol-producing endophytic fungus, Gliocladium sp., from Taxus baccata. Mycobiology 2011;39(3):151-7.

37. Strobel GA. Endophytes as sources of bioactive products. Microb Infect 2003;5(6):535-44.

38. Strobel G, Daisy B. Bioprospecting for microbial endophytes and their natural products. Microbiol Mol Biol Rev 2003;67(4):491-502.

39. Mastan A, Bharadwaj RK, Kushwaha RK, Babu CS. Functional fungal endophytes in Coleus forskohlii regulate labdane diterpene biosynthesis for elevated forskolin accumulation in roots. Microb Ecol 2019;78(4):914-26.

40. Mir RA, Kaushik SP, Chowdery RA, Anuradha M. Elicitation of forskolin in cultures of Rhizactonia bataticola - a phytochemical synthesizing endophytic fungi. Int $\mathrm{J}$ Pharma Pharm Sci 2015;7(10):185-9.

41. Rashmi M, Kushveer JS, Sarma VV. A worldwide list of endophytic fungi with notes on ecology and diversity. Mycosphere 2019;10(1):798-1079.

42. Sakayaroj J, Preedanon S, Supaphon O, Jones EG, Phongpaichit S. Phylogenetic diversity of endophyte assemblages associated with the tropical seagrass Enhalus acoroides in Thailand. Fungal Divers 2010;42(1):27-45.

43. Peršoh D, Melcher M, Flessa F, Rambold G. First fungal community analyses of endophytic ascomycetes associated with Viscum album ssp. austriacum and its host Pinus sylvestris. Fungal Biol 2010;114(7):585-96.

44. Alasbahi RH, Melzig MF. Plectranthus barbatus: a review of phytochemistry, ethnobotanical uses and pharmacology-part 1. Planta Med 2010;76(07):653-61.

\section{How to cite this article:}

Crasta GL, Raveesha KA. Molecular identification of endophytic fungi associated with Coleus forskohlii (Willd.) Briq. J Appl Biol Biotech 2021; 9(06):162-172. 